Review

\title{
Acaricide resistance mechanisms in the two-spotted spider mite Tetranychus urticae and other important Acari: A review
}

\author{
Thomas Van Leeuwen ${ }^{\mathrm{a}, *}$, John Vontas ${ }^{\mathrm{b}}$, Anastasia Tsagkarakou ${ }^{\mathrm{c}}$, Wannes Dermauw ${ }^{\mathrm{a}}$, Luc Tirry ${ }^{\mathrm{a}}$ \\ ${ }^{a}$ Laboratory of Agrozoology, Department of Crop Protection, Faculty of Bioscience Engineering, Ghent University, Coupure links 653, 9000 Ghent, Belgium \\ ${ }^{\mathrm{b}}$ Faculty of Applied Biotechnology and Biology, Department of Biology, University of Crete, Vasilika Vouton, P.O. Box 2208, 71409 Heraklio, Crete, Greece \\ ${ }^{\mathrm{c}}$ National Agricultural Research Foundation (N.AG.RE.F.), Plant Protection Institute of Heraklion, Laboratory of Entomology and Agricultural Zoology, \\ P.O. Box 2228, 71003 Heraklion, Greece
}

\section{A R T I C L E I N F O}

\section{Article history:}

Received 8 April 2010

Received in revised form

27 May 2010

Accepted 31 May 2010

\section{Keywords:}

Tetranychus

Varroa

Rhipicephalus

Sodium channel

Acetylcholinesterase

Cytochrome b

$\mathrm{Q}_{\mathrm{O}} \mathrm{I}$

Point mutations

Resistance mechanisms

Mitochondrial heteroplasmy

Bifenazate

METI

Pyrethroid

\begin{abstract}
A B S T R A C T
The two-spotted spider mite Tetranychus urticae Koch is one of the economically most important pests in a wide range of outdoor and protected crops worldwide. Its control has been and still is largely based on the use of insecticides and acaricides. However, due to its short life cycle, abundant progeny and arrhenotokous reproduction, it is able to develop resistance to these compounds very rapidly. As a consequence, it has the dubious reputation to be the "most resistant species" in terms of the total number of pesticides to which populations have become resistant, and its control has become problematic in many areas worldwide.

Insecticide and acaricide resistance has also been reported in the ectoparasite Sarcoptes scabiei, the causative organism of scabies, and other economically important Acari, such as the Southern cattle tick Rhipicephalus microplus, one of the biggest arthropod threats to livestock, and the parasitic mite Varroa destructor, a major economic burden for beekeepers worldwide.

Although resistance research in Acari has not kept pace with that in insects, a number of studies on the molecular mechanisms responsible for the resistant phenotype has been conducted recently. In this review, state-of-the-art information on $T$. urticae resistance, supplemented with data on other important Acari has been brought together. Considerable attention is given to the underlying resistance mechanisms that have been elucidated at the molecular level. The incidence of bifenazate resistance in $T$. urticae is expanded as an insecticide resistance evolutionary paradigm in arthropods.
\end{abstract}

(c) 2010 Elsevier Ltd. All rights reserved.

\section{Introduction}

The intensive use of insecticides and acaricides has led to resistance in many insect and mite species around the globe. Important crop pests, parasites of livestock, common urban pests and disease vectors have in some cases developed resistance to such extend that their control becomes exceedingly challenging (Table 1) (2008).

The development of insecticide resistance is influenced by many factors, including genetics, biology/ecology and control operations (Georghiou and Taylor, 1977). There are many possible adaptations that permit an insect or mite to survive lethal doses of an insecticide/acaricide. These are usually classified based on their biochemical/physiological properties, as either mechanisms of decreased response to the pesticides (interaction of a pesticide with its target site), or mechanisms of decreased exposure (penetration,

\footnotetext{
* Corresponding author.

E-mail address: thomas.vanleeuwen@ugent.be (T. Van Leeuwen).
}

distribution, metabolism and excretion) (Roush and Tabashnik, 1990; Feyereisen, 1995; Taylor and Feyereisen, 1996). The majority of cases involve changes in the sensitivity of the target site due to point mutations, or sequestration/metabolism of the insecticide before it reaches the target site due to quantitative or qualitative changes in major detoxification enzymes (esterases, P450 monooxygenases and glutathione-S-transferases, reviewed in Oakeshott et al. (2005), Feyereisen (2005), Enayati et al. (2005) and Li et al. (2007)).

Today the major emphasis in resistance research lies on unravelling the underlying molecular mechanisms, in an attempt to use this knowledge to control the development and spread of resistant populations. Molecular analysis allows the identification of specific changes at the genomic level and the subsequent development of robust diagnostics which are essential in resistance management, while the characterisation of detoxification enzymes involved in resistance guides the development of add-ons and 'resistance-breaking' compounds for insecticide formulations. 
Table 1

Top 10 resistant arthropods, based on the number of unique active ingredients for which resistance has been reported and the number of cases reported (Whalon et al., 2008).

\begin{tabular}{|c|c|c|c|c|}
\hline Species & Taxonomy & $\begin{array}{l}\text { Pest } \\
\text { type }\end{array}$ & $\begin{array}{l}\text { No. active } \\
\text { ingredients }\end{array}$ & Cases \\
\hline Tetranychus urticae & Acari: Tetranychidae & Crop & 92 & 367 \\
\hline Plutella xylostella & Lepidoptera: Plutellidae & Crop & 81 & 437 \\
\hline Myzus persicae & Homoptera: Aphididae & Crop & 73 & 320 \\
\hline $\begin{array}{l}\text { Leptinotarsa } \\
\text { decemlineata }\end{array}$ & $\begin{array}{l}\text { Coleoptera: } \\
\text { Chrysomelidae }\end{array}$ & Crop & 51 & 188 \\
\hline Musca domestica & Diptera: Muscidae & Urban & 47 & 195 \\
\hline Blattella germanica & Blattodea: Blattellidae & Urban & 43 & 213 \\
\hline Boophilus microplus & Acari: Ixodidae & Lifestock & 43 & 151 \\
\hline Helicoverpa armigera & Lepidoptera: Noctuidae & Crop & 42 & 608 \\
\hline Bemisia tabaci & Homoptera: Aleyrodidae & Crop & 42 & 281 \\
\hline Panonychus ulmi & Acari: Tetranychidae & Crop & 42 & 181 \\
\hline
\end{tabular}

Although some progress has been made in understanding insecticide/acaricide resistance mechanisms in Acari of major economic importance, knowledge on the mechanisms involved has not kept pace with that in insect pests. This paper reviews the current status of the research on acaricide resistance mechanisms, with particular emphasis on the recently elucidated mechanisms at the molecular level. The two-spotted spider mite Tetranychus urticae is used as key organism, but additional information will be given on three other economically important species: the ectoparasite Sarcoptes scabiei, the causative organism of scabies, the Southern cattle tick Rhipicephalus (Boophilus) microplus, one of the biggest arthropod threats to livestock, and the parasitic mite Varroa destructor (=jacobsoni), a major economic burden for beekeepers worldwide.

\section{Scale of the resistance problem}

\subsection{The two-spotted spider mite T. urticae}

T. urticae Koch is one of the most important pests in many cropping systems worldwide and the most polyphagous species within the family of the Tetranychidae. Its host plants (nearly 800 plant species) comprise of vegetables, fruits, maize, cotton and a wide range of ornamentals (Migeon and Dorkeld, 2010). Although biological control of $T$. urticae has proven successful in many protected crops, insecticides and acaricides have always played the central role in its control in field crops. A large number of compounds with a different chemical structure and mode of action have been used, including neurotoxic insecticides, such as organophosphates and pyrethroids, specific acaricides, such as Mitochondrial Electron Transport Inhibitors (METI's) and organotins, and recently developed compounds such as ketoenols (Knowles, 1997; Dekeyser, 2005; Van Leeuwen et al., 2009). Unfortunately, T. urticae is notorious for its ability to rapidly develop resistance to chemicals (Knowles, 1997; Van Leeuwen et al., 2008). Selection for resistance is accelerated by its high fecundity, inbreeding, arrhenotokous reproduction and very short life cycle resulting in many generations per year, especially in warmer conditions (Cranham and Helle, 1985; Van Leeuwen et al., 2009). These features have led to the fact that this species is currently considered as 'most resistant', in terms of the total number of pesticides to which populations have become resistant (Table 1, reviewed in Van Leeuwen et al. (2009)). A number of resistance mechanisms in T. urticae have been recently characterised at the molecular level (Van Leeuwen et al., 2008; Tsagkarakou et al., 2009; Khajehali et al., 2010; Kwon et al., in press, 2010a; Kwon et al., 2010b).

\subsection{The parasitic itch mite S. scabiei}

Sarcoptic mange or scabies caused by S. scabiei (Acari: Sarcoptidae) affects both animals and humans worldwide. Many active substances, e.g. organochlorines, pyrethroids and the more recent macrocyclic lactones (avermectins and milbemycins), are used extensively for treatment of scabies and the number of reports on resistance concerning these substances is increasing (Currie et al., 2004; Walton et al., 2004; Heukelbach and Feldmeier, 2006). Molecular studies of resistance in itch mites are scarce, however, recent advances may help in overcoming many of the current difficulties in monitoring treatment efficacy and allow the development of more sensitive tools for monitoring emerging resistance (Mounsey et al., 2008). The role of both detoxification enzymes and target-site modifications has been studied most in depth for pyrethroid resistance (Pasay et al., 2006, 2008, 2009). Concerning resistance against other compounds, two studies laid the foundation for further investigations: Mounsey et al. (2006) identified and sequenced $8 \mathrm{ABC}$ transporters in S. scabiei, which are potentially involved in ivermectin resistance and Molin and Mattsson (2008) characterised three recombinant gluthathione transferases which might be involved in the metabolism of acaricides in the itch mite.

\subsection{The major bee pest $V$. destructor}

The parasitic mite $V$. destructor is the most serious arthropod pest of the western honey bee, Apis mellifera. It attaches to the body of bee adults, pupae and larvae and weakens them by sucking hemolymph. In this process, it might vector viruses and other bee disease agents. Beekeepers have limited products to control Varroa. The commonly used varroacides belong to pyrethroids (fluvalinate (Fig. 1A), flumethrine, acrinathrine), formamidines (amitraz (Fig. 1B)), and organophosphates (coumaphos (Fig. 1C)). The occurrence and spread of $V$. destructor resistance is reviewed by Lipinski and Szubstarski (2007). With the exception of pyrethroid resistance, the mechanisms of acaricide resistance in this organism are not well studied.

\subsection{The southern cattle tick Rhipicephalus microplus}

The southern cattle tick $R$. microplus (Canestrini) is one of the biggest arthropod threats to livestock in many parts of the world. This bloodsucking ectoparasite is also able to transmit diseases like Babesia, a blood parasite deadly to cattle. The commonly used compounds for $R$. microplus control include organophosphates and pyrethroids, as well as other tick-detaching agents like amitraz and macrocyclic lactones. Populations that are resistant to organophosphates, pyrethroids and recently amitraz have already been observed in Mexico, the USA and many other regions, with severe economical consequences for cattle growers (Miller et al., 1999, 2007a, 2007b; Soberanes et al., 2002; Li et al., 2004; Miller et al., 2005; Guerrero et al., 2006; Chevillon et al., 2007, Rosario-Cruz et al., 2009a; Rosario-Cruz et al., 2009b). Pyrethroid, organophospate and amitraz resistance has been examined at the molecular level in R. microplus (He et al., 1999; Chen et al., 2007; Temeyer et al., 2007, 2009).

\subsection{Other important Acari}

Other important phytophagous mite species such as the spider mites Tetranychus kanzawai, Tetranychus pacificus, Panonychus ulmi and eryophyoid mites such as Phylocoptruta oleivora are controlled by primarily the same acaricidal compounds as used for T. urticae. Other Ixodid ticks such as Rhipicephalus bursa and Rhipicephalussanguineus are controlled in much the same way as R. microplus. 
A<smiles>CC(C)[C@H](Nc1ccc(C(F)(F)F)cc1Cl)C(=O)OC(C#N)c1cccc(Oc2ccccc2)c1</smiles>

C<smiles>CCOP(=S)(OC)Oc1ccc2c(C)c(Cl)c(=O)oc2c1</smiles>

$\mathbf{E}$<smiles>COC(=O)NNc1cc(-c2ccccc2)ccc1OC</smiles>

$\mathbf{F}$<smiles>CC(C)(C)c1ccc(CSc2cnn(C(C)(C)C)c(=O)c2Cl)cc1</smiles>

B<smiles>CC(N=CN=C=Nc1ccc(C)cc1C)=Nc1ccc(C)cc1C</smiles>

D

$(Z)-(1 R)-$ cis-<smiles>Cc1c(COC(=O)[C@H]2[C@H](C=C(Cl)C(F)(F)F)C2(C)C)cccc1-c1ccccc1</smiles><smiles>Cc1c(COC(=O)[C@H]2[C@@H](C=C(Cl)C(F)(F)F)C2(C)C)cccc1-c1ccccc1</smiles>

(Z)-(1S)-cis-

G

Fig. 1. Chemical structures of economically important acaricides. A) tau-fluvalinate; B) amitraz; C) coumaphos; D) bifenthrin; E) bifenazate; F) pyridaben; G) spirodiclofen.

Recently, the occurrence of resistant populations of these species has been reported (Miller et al., 2001; Auger et al., 2003; Aiki et al., 2005; Enayati et al., 2009; Stavrinides et al., 2010; Van Leeuwen et al., 2010), however, in very few cases attempts were made to study the resistance mechanism.

\section{Resistance mechanisms}

\subsection{Resistance to organophosphates and carbamates}

Organophosphates (OPs) were among the first chemical groups used to control T. urticae. The first failure of chemical control with OPs already occurred in the early fifties. Since then T. urticae has developed resistance to more than 30 OPs and carbamates in 40 countries (reviewed in Van Leeuwen et al. (2009)). OPs and carbamates target acetylcholinesterase (AChE) (EC 3.1.1.7), a key enzyme in the nervous system of both vertebrates and invertebrates. Metabolic OP resistance has been detected directly in some cases by measuring OP metabolism (Voss and Matsumura, 1964) or indirectly by revealing the discrepancies between in vivo resistance and in vitro AChE insensitivity (Zahavi and Tahori, 1970). However, target-site insensitivity seems to be the most common OP resistance mechanism in T. urticae. In 1964 Smissaert was the first to identify AChE insensitivity in T. urticae which was associated with organophosphate resistance (Smissaert, 1964). This discovery provided the "proof of principle" for resistance development in arthropods. Since then, an insensitive AChE has been identified as the mechanism of OP resistance by biochemical genotyping in several T. urticae strains worldwide (Van Leeuwen et al., 2009).

The molecular mechanisms of OP resistance are well understood in insects and have been extensively reviewed (Oakeshott et al., 2005). Most insects and ticks, except higher Diptera, have at least two genes, termed ace- 1 and ace-2, encoding for AChE1 and AChE2, corresponding to the Drosophila paralogous and orthologous genes, but the main synaptic function is encoded by ace-1 (Weill et al., 2002). Up to date, several point mutations have been identified as the cause of OP resistance in insects (Oakeshott et al., 2005). The F331W (Torpedo californica numbering throughout the text) substitution of AChE1, that has been identified and functionally characterised in insects (Oh et al., 2006; Alout et al., 2007) was also found in OP-resistant spider mite strains from Europe (Khajehali et al., 2010) and from Korea (Kwon et al., 2010b), while a different F331C was found in an OP-resistant strain from Japan (Anazawa et al., 2003). The F331W substitution of AChE1 was also implicated in OP resistance in T. kanzawai (Aiki et al., 2005). Additional amino-acid replacements between susceptible and resistant strains were also identified. These include the three known insect resistance mutations G119S, G328A, and A201S found in some OP-resistant T. urticae strains as well as a new mutation A280T detected in all OP-resistant strains from Europe and Korea (Khajehali et al., 2010; Kwon et al., 2010b). A quantitative sequencing protocol and a diagnostic PCR-RFLP were developed to follow the insensitive AChE-based resistance frequency in the field (Khajehali et al., 2010; Kwon et al., 2010b).

Extensive acetylcholinesterase gene duplication was more recently associated with monocrotophos resistance in $T$. urticae, suggesting that resistance has evolved through a combination of mutation accumulation and extensive gene copies (Kwon et al., 2010a). Gene duplications might provide a means of retaining the wild-type susceptible allele, thereby minimizing the possible deleterious effects of mutated resistant alleles. Although speculative, the increased amount of AChE protein encoded by the duplicated genes could enhance the level of resistance by providing more targets for OPs to interact with (Kwon et al., 2010a). 
R. microplus resistance to OPs such as coumaphos, chlorpyrifos and chlorphenvinphos has been recorded (reviewed in RosarioCruz et al. (2009a)) and insensitivity of AChE is considered as an important mechanism of resistance in Mexican tick strains (Rosario-Cruz et al., 2009a). Currently three putative sequences of AChE from $R$. microplus have been reported (Baxter and Barker, 1998; Hernandez et al., 1999; Temeyer et al., 2004). Six mutations were identified in BmAChE3 from a OP-resistant strain of $R$. microplus (Temeyer et al., 2007). The most frequently occurring mutation was a substitution of glutamine $(Q)$ for arginine $(R)$ at position 86 in BmAChE3 (position 66 in mature BmAChE). The role of R86Q was evaluated by expression of the mutant and wild-type cDNA sequences in a baculovirus system. Enzyme kinetics of recombinant BmAChE3 containing or lacking the R86Q mutation demonstrated that the R86Q mutation increased substrate affinity and conferred insensitivity to paraoxon inhibition (Temeyer et al., 2007). Using diagnostic assays, Temeyer et al. (2007, 2009) found that the frequency of this mutation was elevated in OP-resistant tick strains compared to that of OP-susceptible strains. However, a number of susceptible individuals was found to be homozygous for all the six mutations suggesting that none of the mutations alone were sufficient to generate the OP-resistant phenotype at the organism level. The authors concluded that additional mutations in BmAChE3, mutations in additional acetylcholinesterase genes, or additional resistance mechanisms (e.g. oxidative metabolism) that contribute to expression of the OP resistance are likely to occur.

The possible operation of metabolic detoxification pathways in $\mathrm{OP}$ resistance as supporting or major resistance component has been reported, based on synergistic and biochemical/native gels assays (Miller et al., 1999; Jamroz et al., 2000). More recently a serial analysis of gene expression (SAGE) was used to analyze differential gene expression in response to OP treatment with the aim to identify specific genes which are either activated or deactivated when ticks were exposed to coumaphos. A cytochrome P450 was identified which proved to be of particular interest since it was more abundant in treated and untreated OP-resistant larvae compared respectively to treated and untreated OP-susceptible larvae (Guerrero et al., 2007).

\subsection{Resistance to pyrethroids}

Pyrethroids have become a widely favored class of insecticides accounting for a $20 \%$ market share (Khambay and Jewess, 2005). The global decrease of pyrethroid efficacy has provoked research in the nature of resistance towards these compounds in several insects. Conserved point mutations in the voltage gated sodium channel gene have been associated with pyrethroid resistance in a wide range of pests and disease vectors, while metabolic resistance mediated by carboxylesterases or P450s is also well documented (Khambay and Jewess, 2005).

High levels of pyrethroid resistance have been reported in T. urticae populations worldwide with resistance levels scaling over 2000 folds (reviewed in Van Leeuwen et al. (2009)). Several lines of evidence point to either enzymatic hydrolysis by carboxylesterases (COEs), or oxidation by microsomal monooxygenases in the majority of pyrethroid resistance cases in T. urticae (Ay and Gurkan, 2005; Van Leeuwen et al., 2005; Van Leeuwen and Tirry, 2007). However, target-site resistance has been found in a highly resistant strain from Greece (ATHRos-Bf) (Tsagkarakou et al., 2009). Two amino-acid substitutions, a phenylalanine to isoleucine (equivalent to F1538I in Musca domestica) in domain IIIS6 and an alanine to aspartic acid substitution (equivalent to A1215D) within the II/III intracellular interlinker were identified in the ATHRos-Bf strain, compared to susceptible mites (Tsagkarakou et al., 2009) (Fig. 2). It was argued that only the F1538I mutation was important, for several reasons: 1) the same mutation has previously been identified in several pyrethroid resistant strains of the cattle tick R. microplus (He et al., 1999) and 2) it has been shown to confer high levels of resistance in an in vitro model system where it is considered as one of the most highly effective resistance loci for the synthetic pyrethroids found to date (Tan et al., 2005). In addition, a computer generated 3D model of the house fly sodium channel predicts a high-affinity site for pyrethroid binding during channel activation, when the IIS4-S5 linker is pulled closer to the IIS5 and IIIS6 helices and F1538 is one of several aromatic residues that are predicted to interact with alcohol groups of double ringed cyclic pyrethroids, such as bifenthrin (Fig. 1D). Mutations of this residue will destabilise pyrethroid binding and result in resistance (O'Reilly et al., 2006; Davies et al., 2007; Tsagkarakou et al., 2009).

The second mutation A1215D, which is located in the intracellular linker between domains I and II has not been previously associated with resistance in any species. It is possible that this mutation has an additive effect in resistance, in line to I/II linker substitutions which have been shown to strongly synergise the kdr (1014F) resistance mutation (Tan et al., 2005). However, the possibility that this polymorphism away from the binding site is just fixed in the $R$ allele can not be excluded. The mode of inheritance of the target insensitivity-based bifenthrin resistance of the resistant strains from Greece was almost completely recessive (Tsagkarakou et al., 2009).

An additional mutation, L1024V ( $M$. domestica numbering), was proposed to play a major role in knockdown resistance to fenpropathrin, although again its possible role remains to be confirmed by functional studies (Kwon et al., in press). Interestingly, the same study also detected the A1215D mutations reported in the Greek resistant strain, next to deletion of three His-residues (Fig. 2).

High levels of pyrethroid resistance have been also reported in several $V$. destructor populations worldwide. Studies on the mechanisms of Varroa resistance to fluvalinate suggest both metabolic and target-site mediated mechanisms. In Europe and Israel, resistant mites showed increased levels of detoxifying enzymes such as esterases (Gerson et al., 1991) and P450 monooxygenases (Hillesheim et al., 1996; Mozes-Koch et al., 2000). Also, the observed cross resistance between unrelated acaricides such as fluvalinate, coumaphos and amitraz leads one to suspect that resistance is metabolic (Elzen et al., 1998; Sammataro et al., 2005). However, in some reported cases cross resistance was not observed, pointing to an additional mechanisms like target-site resistance, which has been described in pyrethroid resistant Varroa mites from the U.S.A. (Wang et al., 2002) (Fig. 2). Four amino acid changes in the sodium channel have been identified in pyrethroid resistant Varroa mites: F1528L (IIIS6), L1595P (IIIS6-IVS1 linker), I1752V (IVS5) and M1823I (IVS6). Among these, the L1595P and the M1823I were found in resistant $V$. destructor strains from both Michigan and Florida. None of these is found in any other resistant arthropod and their role in resistance remains to be functionally characterised. The full-length cDNA of the sodium channel gene from Varroa ( $\mathrm{VmNa}$ ) has been sequenced by Wang et al. (2003) and this study revealed several novel alternative splicing exons.

High levels of pyrethroid resistance (over 1000 fold) have been identified in the southern cattle tick $R$. microplus (reviewed in Rosario-Cruz et al. (2009a)). Initial synergism experiments suggested that target-site resistance was involved in many cases. While no mutation could be detected in domain II of the sodium channel (where most "kdr" resistant mutations occur in several insect species), the F1538I mutation ( $M$. domestica numbering) in domain III segment 6 (IIIS6) was found to be highly associated with resistance in many studies (He et al., 1999; Enayati et al., 2009; RosarioCruz et al., 2009b) (Fig. 2). Functional characterisation revealed that the mutations substantially decreases the channel sensitivity to pyrethroids (Tan et al., 2005). A diagnostic PCR was developed, and 


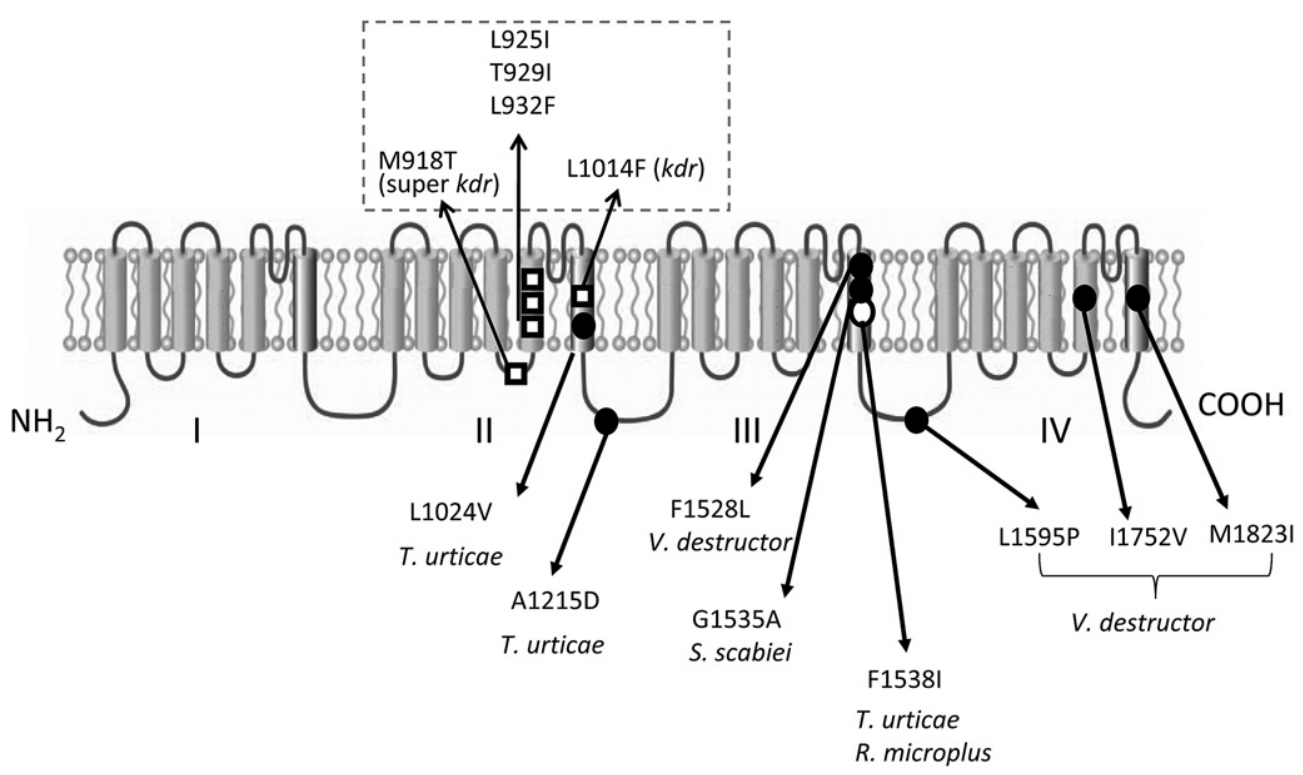

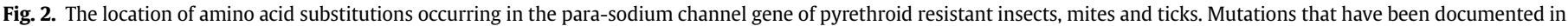

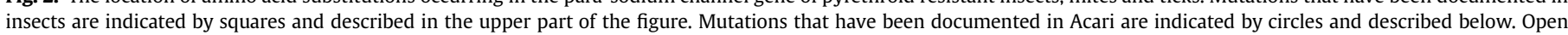
squares and circles indicate mutations that have been functionally characterised and shown to confer pyrethroid resistance.

to date this mutation has been detected in ticks from Mexico, Australia and Brazil (Rosario-Cruz et al., 2009b). However, the absence of the F1538I mutation in two resistant strains with high esterase activity also suggests a role of detoxifying enzymes in $R$. microplus resistance to pyrethroids (Jamroz et al., 2000). A point mutation of a specific esterase gene was found to correlate with resistance and this was supported by an increased permethrin hydrolysis in resistant tick homogenates (Hernandez et al., 2000, 2002; Enayati et al., 2009). A PCR-RFLP method was developed to identify the presence of this mutation and revealed an increased frequency in the resistant strain. Since then, this esterase mutation has been found in numerous Brazilian populations and homozygous individuals have shown to be moderately high resistant to permethrin (Baffi et al., 2007).

Detoxifying enzymes and target-site alteration are also involved in S. scabiei resistance to permethrin. A glycine to aspartic acid change at position 1535 located at IIIS6 of the sodium channel is found in all permethrin resistant itch mites from Australia (Fig. 2). A real time PCR-high resolution melt assay was developed to detect the G1535A mutation, enabling a survey for acaricide resistance development (Pasay et al., 2008). Pasay et al. (2009) examined the effect of synergists on the mortality and on the activity of detoxifying enzymes and concluded that the role of metabolic degradation was of equal importance in permethrin resistant itch mites.

The mite and tick sodium channel genes that have been sequenced show distinct characteristics compared to those of insects, which are a more homogenous group compared to the Arachnida (Tsagkarakou et al., 2009). It is possible that these distinct sequence characteristics are causing the pharmacologically different response of mite and ticks to several pyrethroids compared to insects (Khambay and Jewess, 2005). Alternative splicing, i.e. the mutually exclusive $\mathrm{k} / \mathrm{l}$ exon pair already identified in insects, seems conserved, in T. urticae, but not in V. destructor. The majority of pyrethroid resistance mutations that has been reported in mites and ticks are outside domain II (Fig. 2), where most mutations are found in other species (Khambay and Jewess, 2005). The relatively different types of pyrethroids used against mites and ticks, or the difference in sodium channel characteristics may be associated with this observation.

\subsection{Resistance to bifenazate in T. urticae, a new paradigm}

Bifenazate (Fig. 1E) belongs to the recently discovered acaricidal group of hydrazine derivatives and is nowadays used worldwide for the control of spider mites (Tetranychus spp., Panonychus spp. and Oligonychus spp) on several crops (Dekeyser, 2005). It has been suggested that bifenazate is a pro-acaricide, which needs to be metabolized to its active component, and ester hydrolysis is considered to be the first step in this process (Van Leeuwen et al., 2006; Van Leeuwen et al., 2007). Bifenazate was first thought to be a neurotoxin, since preliminary studies on the mode of action indicated that, at high test concentrations, bifenazate acts on the post-synaptic GABA receptor in the insect nervous system (Dekeyser, 2005). However, recent studies revealed that bifenazate resistance is tightly linked with mutations in the mitochondrial cytochrome b (cytb) and the $\mathrm{Q}_{0}$ site of cytb complex III of the electron transport chain was suggested as an alternative mode of action (Van Leeuwen et al., 2008; Van Nieuwenhuyse et al., 2009) (Fig. 3). This was further supported by a recent study revealing maternally inherited cross resistance between bifenazate and acequinocyl, a well know $\mathrm{Q}_{0}$-site inhibitor of complex III (Van Nieuwenhuyse et al., 2009).

Resistance to bifenazate (over 100,000 fold) was first studied in a laboratory selected T. urticae strain (Van Leeuwen et al., 2006). Synergism studies and enzyme assays revealed that known detoxification routes were most likely not involved in resistance. Reciprocal crosses between susceptible and resistant mites showed that resistance was only inherited maternally (non-Mendelian), which suggested mitochondrial control, a hypothesis supported by experiments showing that bifenazate treatment caused a rapid decline in ATP content and formation (Van Leeuwen et al., 2006). To further elucidate the maternal inheritance, Van Leeuwen et al. (2008) amplified, sequenced and compared complete mitochondrial genomes of susceptible and resistant $T$. urticae mites, revealing only 3 nucleotide substitutions between genomes. The detected point mutations resulted in amino-acid substitution in the mitochondrial cytochrome b (cytb) (G134S, S149F and D169G). These mutations were located in the highly conserved $\mathrm{Q}_{0}$-site region of the protein, more precisely in the cd 1 helix aligning the enzyme 


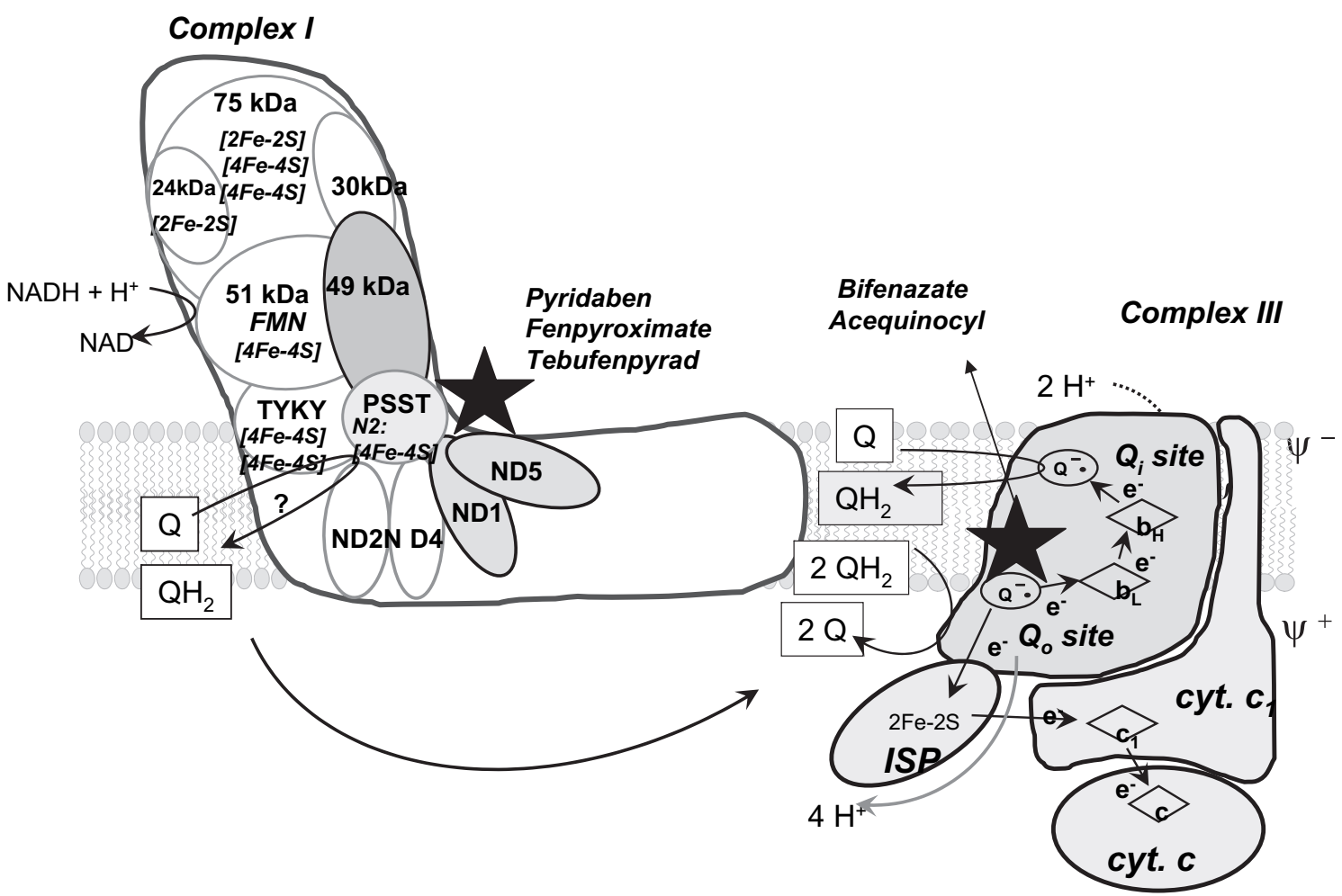

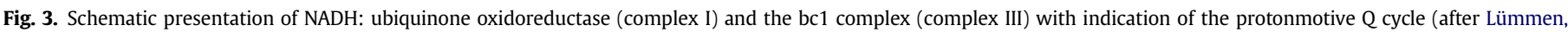

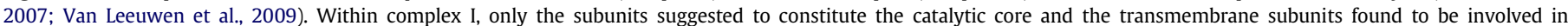

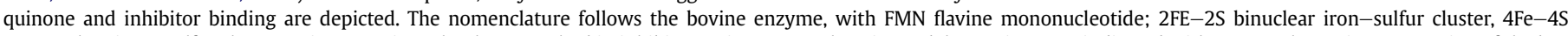

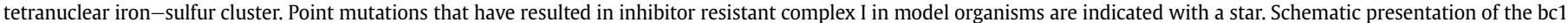

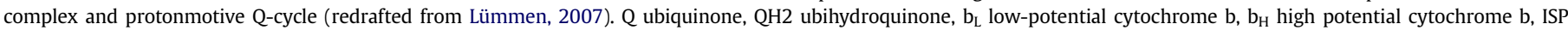

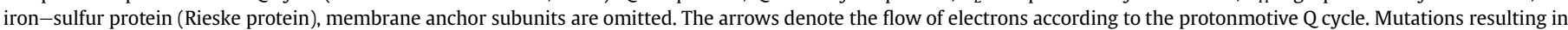
bifenazate and acequinocyl resistance are located in the $\mathrm{Q}_{0}$ site and are indicated with a star.

pocket (Fig. 3), suggesting that bifenazate acts as a $\mathrm{Q}_{0}$ inhibitor in spider mites (Esser et al., 2004; Lümmen, 2007).

Several field strains were subsequently screened for the presence of the cytb resistance mutations with suspected decreased field efficacy of bifenazate (Van Leeuwen et al., 2008). Two more strains were identified containing a G134S mutation identical to that in the laboratory selected strain. In one strain this mutation was accompanied by a second point mutation, I144T, also located in the cd1 helix of the $Q_{0}$ pocket. The combination of these mutations resulted in an extreme high resistance to bifenazate in the field. Interestingly, the strain with a single G134S mutation provided only low protection against bifenazate intoxication, suggesting that a combined effect of at least two mutations in the cd1 helix is necessary to confer high resistance towards bifenazate.

During the screening, a field strain with a new type of mutation was also identified: a P270T substitution in the highly conserved 'PEWY motif at the ef helix, also aligning the $Q_{0}$ pocket of cytb. This was the only detected mutation in this strain, which showed a bifenazate resistance ratio of at least 10,000 (Van Leeuwen et al., 2008).

Van Leeuwen et al. (2008) identified a partially bifenazateresistant strain consisting of heteroplasmic individuals with a $\mathrm{C}$ to $\mathrm{A}$ nucleotide substitution at position 808 in cytb, resulting in the previously described P270T mutation. The mutation frequency in single mites varied between 30 and $98 \%$ and was found to be continuously distributed in the sampled populations. Subsequently the inheritance of heteroplasmy of single fertilised mothers bearing a different and gradually increasing mutation frequency $(37,53,68$, 81 and $96 \%$ A) was investigated. Mutation frequency varied significantly between mothers and their off-spring, especially when the percentage A in the founding mother was low, and it was spread around the initial value in the mother. Even at the lowest initial mutation frequency (37\%), mites in the progeny were found to reach almost the discriminating level of $60 \%$, which had proven to confer a resistant phenotype when treated with the recommended field dose of bifenazate (Van Leeuwen et al., 2008).

Using the observed distributions of variance of the resistant haplotype in the progeny, Van Leeuwen et al. (2008) estimated the magnitude of random processes influencing the segregation and partitioning of mitochondria during reproduction and embryogenesis. Modelling revealed that only a small proportion of the total number of mtDNA molecules likely to occur in mature oocytes where transferred to the next generation, and that this was most likely a random process (Solignac et al., 1984; Van Leeuwen et al., 2008).

It was concluded that a combination of heteroplasmy in an early developmental stage, genetic bottlenecking and sustained selection can lead quickly to the emergence of a resistance phenotype, and drive populations rapidly towards fixation of the resistance trait. This is consistent with observations that most bifenazate-resistant strains investigated so far have been homoplasmic for mutations conferring bifenazate resistance (Van Leeuwen et al., 2008).

\subsection{Resistance to METI acaricides}

The Mitochondrial Electron Transport Inhibitors (METI's) belong to different chemical families (quinazolines, pyrimidinamines, pyrazoles and pyridazinones) but share a similar mode of action: inhibition 
of complex I of the respiratory chain (Hollingworth and Ahammadsahib, 1995; Lümmen, 2007) (Fig. 3). METI compounds like pyridaben (Fig. 1F), tebufenpyrad and fenpyroximate are highly efficient against all life stages of spider mites and are currently used frequently in many crops worldwide.

METI resistance in T. urticae has been reported in a number of geographical different regions and crops (reviewed in Van Leeuwen et al. (2009)). Cross resistance among METIs from different chemical groups has been observed in most cases, suggesting a common resistance mechanism (Stumpf and Nauen, 2001; Van Pottelberge et al., 2009c). Despite their overall different chemical structure, all METIs contain heterocyclic rings with at least one tertiary butylgroup and hydroxylation of this group could be a common mechanisms of oxidative degradations (Stumpf and Nauen, 2001). Studies with synergists and direct measurement of P450 monooxygenase activity support this theory (Stumpf and Nauen, 2001; Kim et al., 2004, 2006; Van Pottelberge et al., 2009c). However, the operation of alternative/additional resistance components has also been suggested by genetic studies (Van Pottelberge et al., 2009c). The clearly monogenic inheritance of fenpyroximate resistance, together with the lack of synergism suggests target-site resistance. METI-acaricides target the proton translocating NADH: ubiquinone ocidoreductase (Fig. 3), one of the most complex structure of all respiratory enzymes. It is believed that the catalytic core of the quinine reduction site of the enzyme consists of subunits TYKY, PSST, ND1, ND5 and the $49 \mathrm{kDa}$ subunit (Lümmen, 2007). Subunits ND1 and ND5 are mitochondrial encoded and possibly not involved, since METI resistance is not maternally inherited. Genetic studies using insecticidal/acaricidal complex I inhibitors as selective agents have already resulted in inhibitor resistant mutants in model organisms, revealing point mutations in the nuclear encoded $49 \mathrm{kDA}$ and PSST subunits (Lümmen, 2007). However, the lack of molecular resolutions of these catalytic core subunits and the difficulty in measuring electron transport over complex I in mitochondrial preparations isolated from mites has impeded research into METI target-site resistance.

\subsection{Avermectins and milbemycins}

Avermectins (abamectin) and milbemycins (milbemectin) belong to the class of macrocyclic lactones and are derived from the soil micro-organisms Streptomyces avermitilis and Streptomyces hygroscopicus, respectively. Avermectins and milbemycins possess excellent miticidal properties. They most likely act on $\gamma$-aminobutyric acid (GABA) and glutamate-gated chloride channels (Fritz et al., 1979; Clark et al., 1995).

There are several reports of abamectin resistance in $T$. urticae in a number of strains and field populations worldwide (Campos et al., 1995; Beers et al., 1998; Stumpf and Nauen, 2002), with resistance ratios mounting up to 668 (Sato et al., 2005).

Few studies have addressed the mechanisms by which spider mites develop resistance to abamectin. Using $\left[{ }^{3} \mathrm{H}\right]$ avermectin $\mathrm{B}_{1 \mathrm{a}}$, Clark et al. (1995) showed that abamectin resistance could result from an increase in excretion and decrease in absorption, combined with high metabolism or conjugation of the compound. Metabolic resistance has been also indirectly implicated in abamectin resistance (Campos et al., 1995; Stumpf and Nauen, 2002).

Macrocyclic lactones (MLs) play a major role in controlling the Southern cattle tick (Shoop et al., 1995; Aguilar-Tipacamu and Rodriguez-Vivas, 2003). Moderate avermectin and ivermectin resistance levels (less than 100 -fold) have been reported in $R$. microplus, but resistance mechanisms have not been investigated (Martins and Furlong, 2001; Perez-Cogollo et al., 2010).

In conclusion, insensitivity of the GABA or glutamate-gated chloride channels, the suggested target sites of avermectins and milbemycins, have not been reported in mites and ticks, although some studies on insects have suggested a decrease in abamectin binding sites (especially the $\alpha$-subunits of the receptor) as a possible resistance mechanism (Clark et al., 1995; Blackhall et al., 1998).

\subsection{Ketoenols}

Ketoenols form a novel class of insecticides/acaricides which chemically belong to the spirocyclic tetronic acid derivatives. Spirodiclofen (Fig. 1G) has been commercialised for the control of mites (Rauch and Nauen, 2002) and acts on mite development, possibly via inhibiting lipid biosynthesis, through selective and potent inhibition of acetyl-CoA carboxylase (ACCase) (Bretschneider et al., 2007).

To assess the risk of spirodiclofen resistance development in T. urticae, Rauch and Nauen (2002) and subsequently Van Pottelberge et al. (2009b) selected laboratory strains with spirodiclofen. After several generations $(>20)$, the resistance ratio rose up to 274 , and combined synergistic, biochemical and metabolism evidence pointed towards an increased oxidative metabolism as the underlying cause (Rauch and Nauen, 2002; Van Pottelberge et al., 2009b). Resistance ratios dropped strikingly when spirodiclofen toxicity was determined on eggs, indicating that targetsite resistance is probably unlikely (Van Pottelberge et al., 2009a).

\subsection{Others}

Organotin compounds have been used worldwide for almost 40 years for the control of $T$. urticae. Resistance has been reported in a number of studies (reviewed in Van Leeuwen et al. (2009)) and a modified target site (oligomycin-sensitive magnesium ATPase) has been hypothesized as the possible underlying resistance mechanism (Knowles, 1997). T. urticae resistance to chlorfenapyr has been reported in Australia and Japan and has been correlated with esterase isozymes and altered activities of general oxidases (reviewed in Van Leeuwen et al. (2009)). T. urticae resistance to dicofol was found in New Zealand, USA, Japan and Europe and is possibly caused by increased degradation (Fergusson-Kolmes et al., 1991). Resistance to mite growth inhibitors (such as clofentezine, hexythiazox and etoxazole) has been detected T. urticae populations in Europe and Australia (reviewed in Van Leeuwen et al. (2009)).

Varroa mites resistant to amitraz have been reported in Mexico (Rodriguez-Dehaibes et al., 2005), the USA (Elzen et al., 1999) and Serbia (Duijn et al., 1997), but the mechanisms conferring resistance have not yet been studied.

Amitraz plays a major role in controlling $R$. microplus and resistant populations have been recently reported (Soberanes et al., 2002; Li et al., 2004; Chevillon et al., 2007). Bioassays with synergists suggest the involvement of P450 cytochrome monooxygenases together with modification of the target site (Ducornez et al., 2005; Chevillon et al., 2007), although resistance levels are rather low. The molecular basis of target-site resistance was examined by comparing sequences of the putative octapamine receptor cDNA, but the sequence of this gene from various Australian amitraz-resistant and amitraz-susceptible cattle ticks was identical (Baxter and Barker, 1999). In contrast, two mutations in octopamine receptor (T8P and L22S) were associated with amitraz resistance in a study performed with $R$. microplus from the US, but further verification is required (Chen et al., 2007).

\section{Future Prospects}

The molecular basis of resistance to many insecticides has been elucidated and resistance associated genes or mutations have been identified in a wide range of insects. More recently, through the availability of whole insect genome sequences, the unravelling of 
the function of complex multi-gene systems in metabolic resistance has become possible. However, it is clear from this review that we are far from completely understanding the importance of these mechanisms in mites and ticks. Resistance research within the Acari has been seriously impeded by the lack of (genome) sequence data. For example, the molecular target sites of a number of chemically diverse acaricidal compounds have not yet been elucidated and characterised at the molecular level. In addition, there is currently very limited molecular information on detoxification genes associated with metabolic resistance, although their importance has been highlighted by numerous biochemical studies in mites and ticks.

In this light, the ongoing effort to sequence and annotate the complete genome of some of the most economically important mite and tick species is very promising. The "Tetranychus urticae Genome Project" ((Grbic et al., 2007), USA Department of Energy, Joint Genome Institute, http://www.jgi.doe.gov/sequencing/why/50028. html) is almost completed and will deliver the complete annotated genomic sequence and large $(>90,000)$ EST data sets that will be integrated in public databases. The "Varroa destructor Genome Project" has been recently initiated and is expected to provide large number of sequence data within 2011-2013 (http://afrsweb.usda.gov/ SP2UserFiles/Place/12750500/VarroaGenomeSketch_Jan072010.pdf). This project aims at delivering a sequenced and analyzed mite genome to public databases and might provide identification of mite genetic factors that affect virulence and acaricide resistance. Many challenges face tick genomics, such as their large genomes ( $>2 \mathrm{Gbp}$ ) and the existence of large amounts of repetitive non-coding DNA. Although BAC libraries have been sequenced of $R$. microplus (Guerrero et al., 2006) the only partially assembled whole genome sequence is that of Ixodes scapularis, the primary tick vector of medical importance in the United States (Nene, 2009). Nevertheless, there are large scale EST data sets available for several species at this moment, e.g. BmiGI, a $R$. microplus database containing over 13000 unique transcripts (Wang et al., 2007). The use of these EST-sequences in microarray design to investigate gene expression of acaricide exposed $R$. microplus larvae has been promising (Saldivar et al., 2008).

The increasing availability of whole genome sequences and EST databases strongly stimulate mite and tick resistance research and will play an important part in determining weak points when developing novel control tools. New information on target-site genes facilitates cloning and mutagenesis studies to determine the precise nature of the mutations and will aid in predicting interactions between mite/tick proteins and acaricides. Genome wide microarrays have been already constructed for some species such as $R$. microplus (Saldivar et al., 2008), or are under development. Together, this will give an unprecedented impetus to toxicology and resistance research in acarology, allowing the dissection of microevolution and environmental adaptation as fundamental processes in resistance development.

Overall, the current genome projects will provide opportunities to move from knowledge and understanding of resistance mechanisms to the practical application in the field, and might deliver novel control tools.

\section{Acknowledgments}

Thomas Van Leeuwen is a Post-doctoral Fellow of the Flemish Research Foundation (FWO).

\section{References}

Aguilar-Tipacamu, G., Rodriguez-Vivas, R.I., 2003. Effect of moxidectin against natural infestation of the cattle tick Boophilus microplus (Acarina: Ixodidae) in the Mexican tropics. Vet. Parasitol. 111, 211-216.
Aiki, Y., Kozaki, T., Mizurio, H., Kono, Y., 2005. Amino acid substitution in Ace paralogous acetylcholinesterase accompanied by organophosphate resistance in the spider mite Tetranychus kanzawai. Pestic. Biochem. Physiol. 82, 154-161.

Alout, H., Berthomieu, A., Hadjivassilis, A., Weill, M., 2007. A new amino-acid substitution in acetylcholinesterase 1 confers insecticide resistance to Culex pipiens mosquitoes from Cyprus. Insect Biochem. Mol. Biol. 37, 41-47.

Anazawa, Y., Tomita, T., Aiki, Y., Kozaki, T., Kono, Y., 2003. Sequence of a cDNA encoding acetylcholinesterase from susceptible and resistant two-spotted spider mite, Tetranychus urticae. Insect Biochem. Mol. Biol. 33, 509-514.

Auger, P., Bonafos, R., Guichou, S., Kreiter, S., 2003. Resistance to fenazaquin and tebufenpyrad in Panonychus ulmi Koch (Acari: Tetranychidae) populations from South of France apple orchards. Crop Prot. 22, 1039-1044.

Ay, R., Gurkan, M.O., 2005. Resistance to bifenthrin and resistance mechanisms of different strains of the two-spotted spider mite (Tetranychus urticae) from Turkey. Phytoparasitica 33, 237-244.

Baffi, M.A., de Souza, G.R.L., Vieira, C.U., de Sousa, C.S., Gourlart, L.R., Bonetti, A.M. 2007. Identification of point mutations in a putative carboxylesterase and their association with acaricide resistance in Rhipicephalus (Boophilus) microplus (Acari: Ixodidae). Vet. Parasitol. 148, 301-309.

Baxter, G.D., Barker, S.C., 1998. Acetylcholinesterase cDNA of the cattle tick, Boophilus microplus: characterisation and role in organophosphate resistance. Insect Biochem. Mol. Biol. 28, 581-589.

Baxter, G.D., Barker, S.C., 1999. Isolation of a cDNA for an octopamine-like, G-protein coupled receptor from the cattle tick, Boophilus microplus. Insect Biochem. Mol. Biol. 29, 461-467.

Beers, E.H., Riedl, H., Dunley, J.E., 1998. Resistance to abamectin and reversion to susceptibility to fenbutatin oxide in spider mite (Acari: Tetranychidae) populations in the Pacific Northwest. J. Econ. Entomol. 91, 352-360.

Blackhall, W.J., Pouliot, J.F., Prichard, R.K., Beech, R.N., 1998. Haemonchus contortus: selection at a glutamate-gated chloride channel gene in ivermectin- and moxidectin-selected strains. Exp. Parasitol. 90, 42-48.

Bretschneider, T., Fischer, R., Nauen, R., 2007. Inhibitors of lipid synthesis (acetyl-CoAcarboxylase inhibitors). In: Krämer, W., Schirmer, U. (Eds.), Modern Crop Protection Compounds. Wiley-VCH Verlag GmbH \& Co, Weinheim, pp. 909-925.

Campos, F., Dybas, R.A., Krupa, D.A., 1995. Susceptibility of 2-spotted spider-mite (Acari, Tetranychidae) populations in California to abamectin. J. Econ. Entomol 88, 225-231.

Chen, A.C., He, H.Q., Davey, R.B., 2007. Mutations in a putative octopamine receptor gene in amitraz-resistant cattle ticks. Vet. Parasitol. 148, 379-383.

Chevillon, C., Ducornez, S., de Meeus, T., Koffi, B.B., Gaia, H., Delathiere, J.M. Barre, N., 2007. Accumulation of acaricide resistance mechanisms in Rhipicephalus (Boophilus) microplus (Acari: Ixodidae) populations from New Caledonia Island. Vet. Parasitol. 147, 276-288.

Clark, J.M., Scott, J.G., Campos, F., Bloomquist, J.R., 1995. Resistance to avermectins extent, mechanisms, and management implications. Annu. Rev. Entomol. 40, $1-30$.

Cranham, J.E., Helle, W., 1985. Pesticide resistance in Tetranychidae. In: Helle, W. Sabelis, M.W. (Eds.), Spider Mites: Their Biology, Natural Ennemies and Control. Elsevier, Amsterdam, pp. 405-421.

Currie, B.J., Harumal, P., McKinnon, M., 2004. First documentation of in vivo and in vitro ivermectin resistance in Sarcoptes scabiei. Clin. Infect. Dis. 39, E8-E12.

Davies, T.G.E., Field, L.M., Usherwood, P.N.R., Williamson, M.S., 2007. DDT, pyrethrins, pyrethroids and insect sodium channels. IUBMB Life 59, 151-162.

Dekeyser, M.A., 2005. Acaricide mode of action. Pest Manag. Sci. 61, 103-110.

Ducornez, S., Barre, N., Miller, R.J., de Garine-Wichatitsky, M., 2005. Diagnosis of amitraz resistance in Boophilus microplus in New Caledonia with the modified Larval Packet test. Vet. Parasitol. 130, 285-292.

Duijn, T., Jovanovic, V., Urakov, D., Milkovic, Z., 1997. Effect of extended utilisation of amitraz-based preparations on the formation of resistant strains of Varroa jacobsoni. Vet. Glas. 45, 851-855.

Elzen, P.J., Eischen, F.A., Baxter, J.B., Pettis, J., Elzen, G.W., Wilson, W.T., 1998. Fluvalinate resistance in Varroa jacobsoni from several geographic locations. Am. Bee J. 138, 674-676.

Elzen, P.J., Baxter, J.R., Spivak, M., Wilson, W.T., 1999. Amitraz resistance in varroa: new discovery in North America. Am. Bee J. 139, pp. 362-362.

Enayati, A.A., Ranson, H., Hemingway, J., 2005. Insect glutathione transferases and insecticide resistance. Insect Mol. Biol. 14, 3-8.

Enayati, A.A., Asgarian, F., Sharif, M., Boujhmehrani, H., Amouei, A., Vahedi, N., Boudaghi, B., Piazak, N., Hemingway, J., 2009. Propetamphos resistance in Rhipicephalus bursa (Acari, Ixodidae). Vet. Parasitol. 162, 135-141.

Esser, L., Quinn, B., Li, Y.F., Zhang, M.Q., Elberry, M., Yu, L., Yu, C.A., Xia, D., 2004 Crystallographic studies of quinol oxidation site inhibitors: a modified classification of inhibitors for the cytochrome bc(1) complex. J. Mol. Biol. 341, 281-302.

Fergusson-Kolmes, L.A., Scott, J.G., Dennehy, T.J., 1991. Dicofol resistance in Tetranychus urticae (Acari, Tetranychidae) - cross-resistance and pharmacokinetics. J. Econ. Entomol. 84, 41-48.

Feyereisen, R., 1995. Molecular biology of insecticide resistance. Toxicol. Lett. 82-3, 83-90.

Feyereisen, R., 2005. Insect cytochrome P450. In: Iatrou, K., Gilbert, L.I., Gill, S.S. (Eds.), Comprehensive Molecular Insect Science, vol. 5. Elsevier, Oxford UK, pp. $1-77$.

Fritz, L.C., Wang, C.C., Gorio, A., 1979. Avermectin-B1A irreversibly blocks postsynaptic potentials at the loboster neuromuscular-junction by reducing muscle membrane resistance. Proc. Natl. Acad. Sci. U.S.A. 76, 2062-2066. 
Georghiou, G.P., Taylor, C.E., 1977. Genetic and biological influences in evolution of insecticide resistance. J. Econ. Entomol. 70, 319-323.

Gerson, U., Mozeskoch, R., Cohen, E., 1991. Enzyme levels used to monitor pesticide resistance in Varroa jacobsoni. J. Apic. Res. 30, 17-20.

Grbic, M., Khila, A., Lee, K.Z., Bjelica, A., Grbic, V., Whistlecraft, J., Verdon, L., Navajas, M., Nagy, L., 2007. Mity model: Tetranychus urticae, a candidate for chelicerate model organism. BioEssays 29, 489-496.

Guerrero, F.D., Nene, V.M., George, J.E., Barker, S.C., Willadsen, P., 2006. Sequencing a new target genome: the Boophilus microplus (Acari: Ixodidae) genome project. J. Med. Entomol. 43, 9-16.

Guerrero, F.D., Bendele, K.G., Chen, A.C., Li, A.Y., Miller, R.J., Pleasance, E., Varhol, R., Rousseau, M.E., Nene, V.M., 2007. Serial analysis of gene expression in the southern cattle tick following acaricide treatment of larvae from organophosphate resistant and susceptible strains. Insect Mol. Biol. 16, 49-60.

He, H.Q., Chen, A.C., Davey, R.B., Ivie, G.W., George, J.E., 1999. Identification of a point mutation in the para-type sodium channel gene from a pyrethroid-resistant cattle tick. Biochem. Biophys. Res. Commun. 261, 558-561.

Hernandez, R., He, H.Q., Chen, A.C., Ivie, G.W., George, J.E., Wagner, G.G., 1999 Cloning and sequencing of a putative acetylcholinesterase cDNA from Boophilus microplus (Acari: Ixodidae). J. Med. Entomol. 36, 764-770.

Hernandez, R., He, H.Q., Chen, A.C., Waghela, S.D., Ivie, G.W., George, J.E., Wagner, G.G. 2000. Identification of a point mutation in an esterase gene in different populations of the southern cattle tick, Boophilus microplus. Insect Biochem. Mol. Biol. 30, 969-977.

Hernandez, R., Guerrero, F.D., George, J.E., Wagner, G.G., 2002. Allele frequency and gene expression of a putative carboxylesterase-encoding gene in a pyrethroid resistant strain of the tick Boophilus microplus. Insect Biochem. Mol. Biol. 32 1009-1016.

Heukelbach, J., Feldmeier, H., 2006. Scabies. Lancet 367, 1767-1774.

Hillesheim, E., Ritter, W., Bassand, D., 1996. First data on resistance mechanisms of Varroa jacobsoni (OUD) against tau-fluvalinate. Exp. Appl. Acarol. 20, 283-296.

Hollingworth, R.M., Ahammadsahib, K.I., 1995. Inhibitors of respiratory complex I: mechanisms, pesticidal actions and toxicology. Rev. Pestic. Toxicol. 3, 277-302.

Jamroz, R.C., Guerrero, F.D. Pruett, J.H., Oehler, D.D., Miller, R.J., 2000. Molecular and biochemical survey of acaricide resistance mechanisms in larvae from Mexican strains of the southern cattle tick, Boophilus microplus. J. Insect Physiol. 46, 685-695.

Khajehali, J., Van Leeuwen, T., Grispou, M., Morou, E., Alout, H., Weill, M., Tirry, L Vontas, J., Tsagkarakou, A., 2010. Acetylcholinesterase point mutations in European strains of Tetranychus urticae (Acari: Tetranychidae) resistant to organophosphates. Pest Manag. Sci. 66, 220-228.

Khambay, B., Jewess, P., 2005. Pyrethroids. In: Iatrou, K., Gilbert, L.I., Gill, S.S. (Eds.), Comprehensive Molecular Insect Science, vol. 6. Elsevier, Oxford UK, pp. 1-29.

Kim, Y.J., Lee, S.H., Lee, S.W., Ahn, Y.J., 2004. Fenpyroximate resistance in Tetranychus urticae (Acari: Tetranychidae): cross-resistance and biochemical resistance mechanisms. Pest Manag. Sci. 60, 1001-1006.

Kim, Y.J., Park, H.M., Cho, J.R., Ahn, Y.J., 2006. Multiple resistance and biochemical mechanisms of pyridaben resistance in Tetranychus urticae (Acari: Tetranychidae). J. Econ. Entomol. 99, 954-958.

Knowles, C.O., 1997. Mechanisms of resistance to acaricides. In: Sjut, V. (Ed.), Molecular Mechanisms of Resistance to Agrochemicals. Springer, New York, pp. 57-77.

Kwon, D.H., Clark, J.M., Lee, S.H., 2010a. Extensive gene duplication of acetylcholinesterase associated with organophosphate resistance in the two-spotted spider mite. Insect Mol. Biol. 19, 195-204.

Kwon, D.H., Im, J.S., Ahn, J.J., Lee, J.H., Clark, J.M., Lee, S.H., 2010b. Acetylcholinesterase point mutations putatively associated with monocrotophos resistance in the two-spotted spider mite. Pestic. Biochem. Physiol. 96, 36-42.

Kwon, D.H., Clark, J.M., Lee, S.H., Cloning of a sodium channel gene and identification of mutations putatively associated with fenpropathrin resistance in Tetranychus urticae. Pestic. Biochem. Physiol., in press, doi:10.1016/j.pestbp. 2009.1007.1009.

Li, A.Y., Davey, R.B., Miller, R.J., George, J.E., 2004. Detection and characterization of amitraz resistance in the southern cattle tick, Boophilus microplus (Acari: Ixodidae). J. Med. Entomol. 41, 193-200.

Li, X.C., Schuler, M.A., Berenbaum, M.R., 2007. Molecular mechanisms of metabolic resistance to synthetic and natural xenobiotics. Annu. Rev. Entomol. 52, 231-253.

Lipinski, Z., Szubstarski, J., 2007. Resistance of Varroa destructor to most commonly used synthetic acaricides. Pol. J. Vet. Sci. 10, 289-294.

Lümmen, P., 2007. Mitochondrial electron transport complexes as biochemical target sites for insecticides and acaricides. In: Ishaaya, I., Nauen, R., Horowitz, A. R. (Eds.), Insecticides Design Using Advanced Technologies. Springer Verlag, Berlin, Heidelberg, pp. 197-215.

Martins, J.R., Furlong, J., 2001. Avermectin resistance of the cattle tick Boophilus microplus in Brazil. Vet. Rec. 149, pp. 64-64.

Migeon, A., Dorkeld, F., 2010. Spider Mites Web: a Comprehensive Database for the Tetranychidae. http://www.montpellier.inra.fr/CBGP/spmweb.

Miller, R.J., Davey, R.B., George, J.E., 1999. Characterization of pyrethroid resistance and susceptibility to coumaphos in Mexican Boophilus microplus (Acari: Ixodidae). J. Med. Entomol. 36, 533-538.

Miller, R.J., George, J.E., Guerrero, F., Carpenter, L., Welch, J.B., 2001. Characterization of acaricide resistance in Rhipicephalus sanguineus (Latreille) (Acari: Ixodidae) collected from the Corozal Army Veterinary Quarantine Center, Panama. J. Med. Entomol. 38, 298-302.
Miller, R.J., Davey, R.B., George, J.E., 2005. First report of organophosphate-resistant Boophilus microplus (Acari: Ixodidae) within the United States. J. Med. Entomol. 42, 912-917.

Miller, R.J., Davey, R.B., George, J.E., 2007a. First report of permethrin-resistant Boophilus microplus (Acari: Ixodidae) collected within the United States. J. Med. Entomol. 44, 308-315.

Miller, R.J., Rentaria, J.A.E., Martinez, H.Q., George, J.E., 2007b. Characterization of permethrin-resistant Boophilus microplus (Acari: Ixodidae) collected from the state of coahuila, Mexico. J. Med. Entomol. 44, 895-897.

Molin, E.U., Mattsson, J.G., 2008. Effect of acaricides on the activity of glutathione transferases from the parasitic mite Sarcoptes scabiel. Parasitology 135, 115-123.

Mounsey, K.E., Holt, D.C., McCarthy, J., Walton, S.F., 2006. Identification of ABC transporters in Sarcoptes scabiei. Parasitology 132, 883-892.

Mounsey, K.E., Holt, D.C., McCarthy, J., Currie, B.J., Walton, S.F., 2008. Scabies: molecular perspectives and therapeutic implications in the face of emerging drug resistance. Future Microbiol. 3, 57-66.

Mozes-Koch, R., Slabezki, Y., Efrat, H., Kalev, H., Kamer, Y., Yakobson, B.A., Dag, A., 2000. First detection in Israel of fluvalinate resistance in the varroa mite using bioassay and biochemical methods. Exp. Appl. Acarol. 24, 35-43.

Nene, V., 2009. Tick genomics - coming of age. Front. Biosci. 14, 2666-2673.

Oakeshott, J.G., Claudianos, C., Campbell, P.M., Newcomb, R.D., Russel, R.J., 2005. Biochemical genetics and genomics of insect esterases. In: Iatrou, K., Gilbert, L.I., Gill, S.S. (Eds.), Comprehensive Molecular Insect Science, vol. 5. Elsevier, Oxford UK, pp. 309-382.

Oh, S.H., Kozaki, T., Mizuno, H., Tomita, T., Kono, Y., 2006. Expression of Aceparalogous acetylcholinesterase of Culex tritaeniorhynchus with an amino acid substitution conferring insecticide insensitivity in baculovirus-insect cell system. Pestic. Biochem. Physiol. 85, 46-51.

O’Reilly, A.O., Khambay, B.P.S., Williamson, M.S., Field, L.M., Wallace, B.A., Davies, T.G.E., 2006. Modelling insecticide-binding sites in the voltage-gated sodium channel. Biochem. J. 396, 255-263.

Pasay, C., Walton, S., Fischer, K., Holt, D., McCarthy, J., 2006. Pcr-based assay to survey for knockdown resistance to pyrethroid acaricides in human scabies mites (Sarcoptes scabiei var Hominis). Am. J. Trop. Med. Hyg. 74, 649-657.

Pasay, C., Arlian, L., Morgan, M., Vyszenski-Moher, D., Rose, A., Holt, D., Walton, S., McCarthy, J., 2008. High-resolution melt analysis for the detection of a mutation associated with permethrin resistance in a population of scabies mites. Med. Vet. Entomol. 22, 82-88.

Pasay, C., Arlian, L., Morgan, M., Gunning, R., Rossiter, L., Holt, D., Walton, S., Beckham, S., McCarthy, J., 2009. The effect of insecticide synergists on the response of scabies mites to pyrethroid acaricides. Plos Neglect. Trop. Dis. 3.

Perez-Cogollo, L.C., Rodriguez-Vivas, R.I., Ramirez-Cruz, G.T., Miller, R.J., 2010. First report of the cattle tick Rhipicephalus microplus resistant to ivermectin in Mexico. Vet. Parasitol. 168, 165-169.

Rauch, N., Nauen, R., 2002. Spirodiclofen resistance risk assessment in Tetranychus urticae (Acari: Tetranychidae): a biochemical approach. Pestic. Biochem. Physiol. 74, 91-101.

Rodriguez-Dehaibes, S.R., Otero-Colina, G., Sedas, V.P., Jimenez, J.A.V., 2005. Resistance to amitraz and flumethrin in Varroa destructor populations from Veracruz, Mexico. J. Apic. Res. 44, 124-125.

Rosario-Cruz, R., Almazan, C., Miller, R.J., Dominguez-Garcia, D.I., HernandezOrtiz, R., de la Fuente, J., 2009a. Genetic basis and impact of tick acaricide resistance. Front. Biosci. 14, 2657-2665.

Rosario-Cruz, R., Guerrero, F.D., Miller, R.J., Rodriguez-Vivas, R.I., Tijerina, M., Dominguez-Garcia, D.I., Hernandez-Ortiz, R., Cornel, A.J., McAbee, R.D., AlonsoDiaz, M.A., 2009b. Molecular survey of pyrethroid resistance mechanisms in Mexican field populations of Rhipicephalus (Boophilus) microplus. Parasitol. Res. $105,1145-1153$.

Roush, R.T., Tabashnik, B., 1990. Pesticide Resistance in Arthropods. Chapman and Hall, New York.

Saldivar, L., Guerrero, F.D., Miller, R.J., Bendele, K.G., Gondro, C., Brayton, K.A., 2008. Microarray analysis of acaricide-inducible gene expression in the southern cattle tick, Rhipicephalus (Boophilus) microplus. Insect Mol. Biol. 17, 597-606.

Sammataro, D., Untalan, P., Guerrero, F., Finley, J., 2005. The resistance of varroa mites (Acari: Varroidae) to acaricides and the presence of esterase. Int. J. Acarol. 31, 67-74.

Sato, M.E., Da Silva, M.Z., Raga, A., De Souza, M.F., 2005. Abamectin resistance in Tetranychus urticae Koch (Acari: Tetranychidae): selection, cross-resistance and stability of resistance. Neotrop. Entomol. 34, 991-998.

Shoop, W.L., Mrozik, H., Fisher, M.H., 1995. Structure and activity of avermectins and milbemycins in animal health. Vet. Parasitol. 59, 139-156.

Smissaert, H.R., 1964. Cholinesterase inhibition in spider mites susceptible + resistant to organophosphate. Science 143, 129-131.

Soberanes, N.C., Santamaria, M.V., Fragoso, H.S., Garcia, Z.V., 2002. First case reported of amitraz resistance in the southern cattle tick Boophilus microplus in Mexico. Tec. Pecu. Mex. 40, 81-92.

Solignac, M., Genermont, J., Monnerot, M., Mounolou, J.C., 1984. Genetics of mitochondria in Drosophila - mtDNA inheritance in heteroplasmic strains of Drosophila mauritiana. Mol. Gen. Genet. 197, 183-188.

Stavrinides, M.C., Van Nieuwenhuyse, P., Van Leeuwen, T., Mills, N.J., 2010. Development of acaricide resistance in Pacific spider mite (Tetranychus pacificus) from California vineyards. Exp. Appl. Acarol. 50, 243-254.

Stumpf, N., Nauen, R., 2001. Cross-resistance, inheritance, and biochemistry of mitochondrial electron transport inhibitor-acaricide resistance in Tetranychus urticae (Acari: Tetranychidae). J. Econ. Entomol. 94, 1577-1583. 
Stumpf, N., Nauen, R., 2002. Biochemical markers linked to abamectin resistance in Tetranychus urticae (Acari: Tetranychidae). Pestic. Biochem. Physiol. 72, 111-121.

Tan, J.G., Liu, Z.Q., Wang, R.W., Huang, Z.Y., Chen, A.C., Gurevitz, M., Dong, K., 2005. Identification of amino acid residues in the insect sodium channel critical for pyrethroid binding. Mol. Pharmacol. 67, 513-522.

Taylor, C.E., Feyereisen, R., 1996. Molecular biology and evolution of resistance of toxicants. Mol. Biol. Evol. 13, 719-734.

Temeyer, K.B., Davey, R.B., Chen, A.C., 2004. Identification of a third Boophilus microplus (Acari: Ixodidae) cDNA presumptively encoding an acetylcholinesterase. J. Med. Entomol. 41, 259-268.

Temeyer, K.B., Pruett, J.H., Olafson, P.U., Chen, A.C., 2007. R86Q a mutation in BmAChE3 yielding a Rhipicephalus microplus organophosphate-insensitive acetylcholinesterase. J. Med. Entomol. 44, 1013-1018.

Temeyer, K.B., Olafson, P.U., Miller, R.J., 2009. Genotyping mutations in BmAChE3: a survey of organophosphate-resistant and -Susceptible strains of Rhipicephalus (Boophilus) microplus. J. Med. Entomol. 46, 1355-1360.

Tsagkarakou, A., Van Leeuwen, T., Khajehali, J., Ilias, A., Grispou, M., Williamson, M. S., Tirry, L., Vontas, J., 2009. Identification of pyrethroid resistance associated mutations in the para sodium channel of the two-spotted spider mite Tetranychus urticae (Acari: Tetranychidae). Insect Mol. Biol. 18, 583-593.

Van Leeuwen, T., Tirry, L., 2007. Esterase-mediated bifenthrin resistance in a multiresistant strain of the two-spotted spider mite, Tetranychus urticae. Pest Manag. Sci. 63, 150-156.

Van Leeuwen, T., Van Pottelberge, S., Tirry, L., 2005. Comparative acaricide susceptibility and detoxifying enzyme activities in field-collected resistant and susceptible strains of Tetranychus urticae. Pest Manag. Sci. 61, 499-507.

Van Leeuwen, T., Tirry, L., Nauen, R., 2006. Complete maternal inheritance of bifenazate resistance in Tetranychus urticae Koch (Acari: Tetranychidae) and its implications in mode of action considerations. Insect Biochem. Mol. Biol. 36, 869-877.

Van Leeuwen, T., Van Pottelberge, S., Nauen, R., Tirry, L., 2007. Organophosphate insecticides and acaricides antagonise bifenazate toxicity through esterase inhibition in Tetranychus urticae. Pest Manag. Sci. 63, 1172-1177.

Van Leeuwen, T., Vanholme, B., Van Pottelberge, S., Van Nieuwenhuyse, P., Nauen, R., Tirry, L., Denholm, I., 2008. Mitochondrial heteroplasmy and the evolution of insecticide resistance: non-Mendelian inheritance in action. Proc. Natl. Acad. Sci. U.S.A 105, 5980-5985.

Van Leeuwen, T., Vontas, J., Tsagkarakou, A., 2009. Mechanisms of acaricide resistance in the two spotted spider mite Tetranychus urticae. In: Ishaaya, I., Horowitz, A.R. (Eds.), Biorational Control of Arthropod Pests. Springer, The Netherlands, pp. 347-393.
Van Leeuwen, T., Witters, J., Nauen, R., Duso, C., Tirry, L., 2010. The control of eriophyid mites: state of the art and future challenges. Exp. Appl. Acarol. 51, 205-224.

Van Nieuwenhuyse, P., Van Leeuwen, T., Khajehali, J., Vanholme, B., Tirry, L., 2009 Mutations in the mitochondrial cytochrome b of Tetranychus urticae Koch (Acari: Tetranychidae) confer cross-resistance between bifenazate and acequinocyl. Pest Manag. Sci. 65, 404-412.

Van Pottelberge, S., Khajehali, J., Van Leeuwen, T., Tirry, L., 2009a. Effects of spirodiclofen on reproduction in a susceptible and resistant strain of Tetranychus urticae (Acari: Tetranychidae). Exp. Appl. Acarol. 47, 301-309.

Van Pottelberge, S., Van Leeuwen, T., Khajehali, J., Tirry, L., 2009b. Genetic and biochemical analysis of a laboratory-selected spirodiclofen-resistant strain of Tetranychus urticae Koch (Acari: Tetranychidae). Pest Manag. Sci. 65, 358-366.

Van Pottelberge, S., Van Leeuwen, T., Nauen, R., Tirry, L., 2009c. Resistance mechanisms to mitochondrial electron transport inhibitors in a field-collected strain of Tetranychus urticae Koch (Acari: Tetranychidae). Bull. Entomol. Res. 99, 23-31.

Voss, G., Matsumura, F., 1964. Resistance to organophosphorus compunds in 2-spotted spider mite -2 different mechanisms of resistance. Nature 202, 319-320.

Walton, S.F., D.C., H., Currie, B.J., Kemp, D.J., 2004. Scabies: new future for a neglected disease. Adv. Parasitol. 57, 309-376.

Wang, R.W., Liu, Z.Q., Dong, K., Elzen, P.J., Pettis, J., Huang, Z.Y., 2002. Association of novel mutations in a sodium channel gene with fluvalinate resistance in the mite, Varroa destructor. J. Apic. Res. 41, 17-25.

Wang, R.W., Huang, Z.Y., Dong, K., 2003. Molecular characterization of an arachnid sodium channel gene from the varroa mite (Varroa destructor). Insect Biochem. Mol. Biol. 33, 733-739.

Wang, M.H., Guerrero, F.D., Pertea, G., Nene, V.M., 2007. Global comparative analysis of ESTs from the southern cattle tick, Rhipicephalus (Boophilus) microplus. BMC Genomics 8.

Weill, M., Fort, P., Berthomieu, A., Dubois, M.P., Pasteur, N., Raymond, M., 2002. A novel acetylcholinesterase gene in mosquitoes codes for the insecticide target and is non-homologous to the ace gene in Drosophila. Proc. R. Soc. B-Biol. Sci. 269, 2007-2016.

Whalon, M.E., Mota-Sanchez, R.M., Hollingworth, R.M., Duynslager, L. 2008. Artrhopods Resistant to Pesticides Database (ARPD). http://www. pesticideresistance.org

Zahavi, M., Tahori, A.S., 1970. Sensitivity of acetylcholinesterase in spider mites to organo-phosphorus compounds. Biochem. Pharmacol. 19, 219-225. 